\title{
Proteinosis alveolar idiopática. La presentación común de una rara enfermedad
}

\author{
Idiopathic alveolar proteinosis. The common \\ presentation of a rare disease
}

Julia Edith Chamorro, MD('); Julián Darío ÑÁÑEZ, MD(); RAMIRo PINEdo, MD(3)

\begin{abstract}
Resumen
La proteinosis alveolar pulmonar es una rara entidad de etiología aún desconocida que se caracteriza por la acumulación anormal de material lipoproteináceo dentro de los alvéolos. En la actualidad se pueden identificar tres formas de presentación (congénita, secundaria y adquirida), las cuales tienen como común denominador el extenso compromiso pulmonar. Las alteraciones primarias incluyen una disminución en la depuración del surfactante o un incremento en la producción del mismo, alteraciones que implican defectos genéticos que alteran las proteínas que componen al surfactante o al receptor del GM-CSF (por su sigla en inglés, Granulocyte-macrophage colony-stimulating factor). Su presentación adquirida cursa con la presencia de anticuerpos anti GM/CSF, resaltando así el rol de esta sustancia en la homeostasis del surfactante. En esta ocasión, se presenta el caso de una paciente joven con un cuadro de sintomatología respiratoria baja en quien se destaca la escasa correlación entre su apariencia clínica y su extenso compromiso parenquimatoso pulmonar.
\end{abstract}

Palabras clave: proteinosis alveolar pulmonar, fosfolipoproteinosis alveolar pulmonar.

\begin{abstract}
Pulmonary alveolar proteinosis (PAP) is a rare condition of unknown etiology that is characterized by an abnormal accumulation of lipoproteinaceus material within the alveoli. Today, three types of presentations have been identified (congenital, secondary and acquired) which have, as a common denominator, an extensive lung involvement. Primary alterations include a decrease in the clearance of surfactant or an increase in the production thereof, alterations involving genetic defects that alter the proteins that comprise the surfactant or the receptor of GM - CSF. The acquired presentation is characterized by the presence of anti - GM-CSF antibodies, thus highlighting the role of this substance in surfactant homeostasis.

On this occasion, we present the case of a young female patient with lower respiratory symptoms, in whom, the low correlation between clinical appearance and extensive pulmonary parenchymal compromise is a remarkable feature.
\end{abstract}

Keywords: pulmonary alveolar proteinosis, pulmonary alveolar phospholipoproteinosis.

\begin{abstract}
Caso
Paciente de sexo femenino, de 30 años de edad, docente de artes plásticas, con antecedente de alergias al polvo, la humedad y los cambios de temperatura e historia de consumo de hasta tres cigarrillos al día desde hace quince años. Consultó por cuadro clínico de cuatro meses de evolución conformado por tos húmeda intermitente que interfería con el sueño, escasamente productiva, de esputo amarillento no hemoptoico, asociado a disnea de grandes esfuerzos, congestión nasal, aclaramiento y prurito faríngeo que no mejoraba con la administración de antihistamínicos. Su exploración física mostró a una paciente en adecuadas condiciones generales, afebril, con estertores finos
\end{abstract}


"en velcro" a nivel basal bilateral sin sibilancias, con evidencia de cianosis central y distal asociada a hipocratismo digital grado II.

El hemograma reveló solamente poliglobulia $(\mathrm{Hb}$ $17 \mathrm{~g} / \mathrm{dL}$ ), con un perfil inmunológico donde se observaron ANA's positivos - patrón moteado - 1:160, una serología (VDRL) no reactiva y una prueba rápida de VIH - negativa. Los reactantes de fase aguda y los niveles de complemento sérico se encuentran dentro de límites normales. La espirometría es compatible con una alteración ventilatoria restrictiva moderada $(\mathrm{CVF}$ - capacidad vital forzada $=59 \%)$ que mejoró significativamente con la administración de beta 2 inhalado (relación FEV1 / CVF = 63 \%). La radiografía de tórax inicial reveló la presencia de extensas y múltiples opacidades parenquimatosas bilaterales con tendencia a la consolidación, las cuales respetaban ambos ápices pulmonares.

Una tomografía axial computarizada de alta resolución del tórax (TCAR) confirmó la presencia de opacidades difusas del parénquima pulmonar con patrón en "vidrio esmerilado" y "empedrado" (figuras 1 y 2). Las tinciones y cultivos de esputo fueron negativas para determinar bacterias, micobacterias $\mathrm{u}$ hongos.

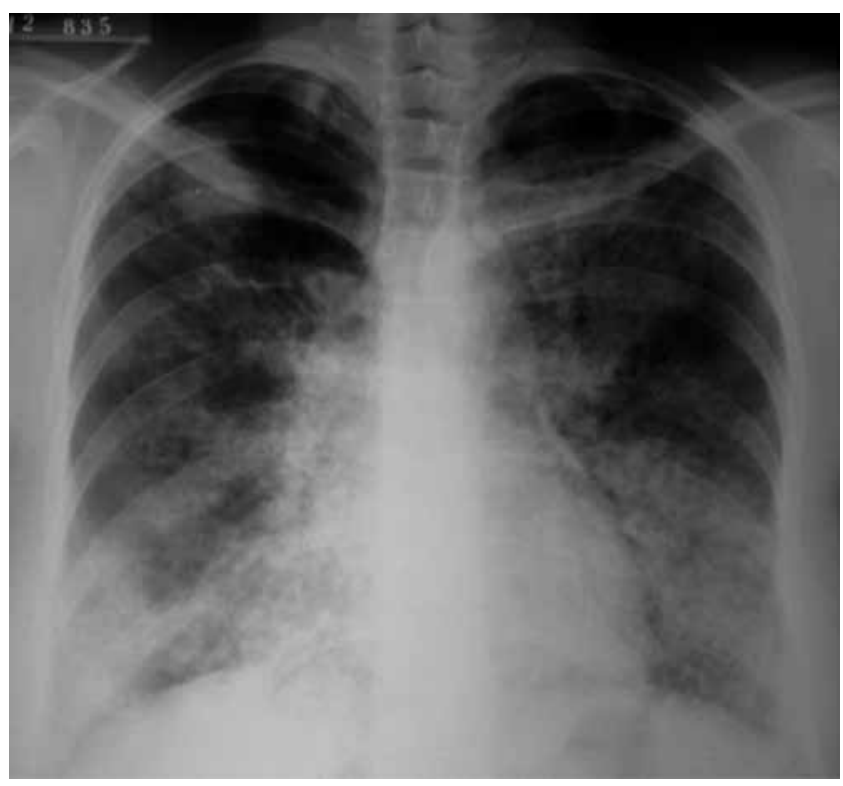

Figura 1. Radiografía de tórax que revela la presencia de múltiples opacidades alveolares difusas en ambos campos pulmonares.
Inicialmente recibió manejo empírico con prednisolona $10 \mathrm{mg} /$ día con mejoría de la disnea y los episodios de tos, manteniéndose en clase funcional I.

Se ordenó toma de biopsia pulmonar que reveló marcada distensión alveolar dada por abundante cantidad de material eosinofílico granular con coloración PAS positivo y numerosas agujas de colesterol, neumocitos tipo II hiperplásicos y fibrosis intersticial leve con signos de inflamación crónica, hallazgos concordantes con proteinosis alveolar (figuras 3 a 5).

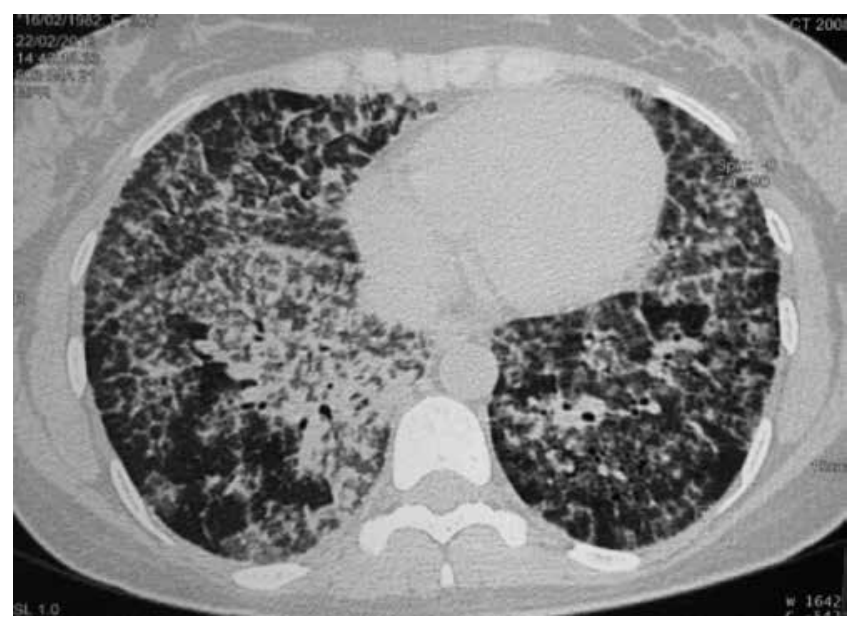

Figura 2. Escanografía de tórax que muestra opacidades difusas del parénquima pulmonar con patrón en "vidrio esmerilado" y "empedrado".

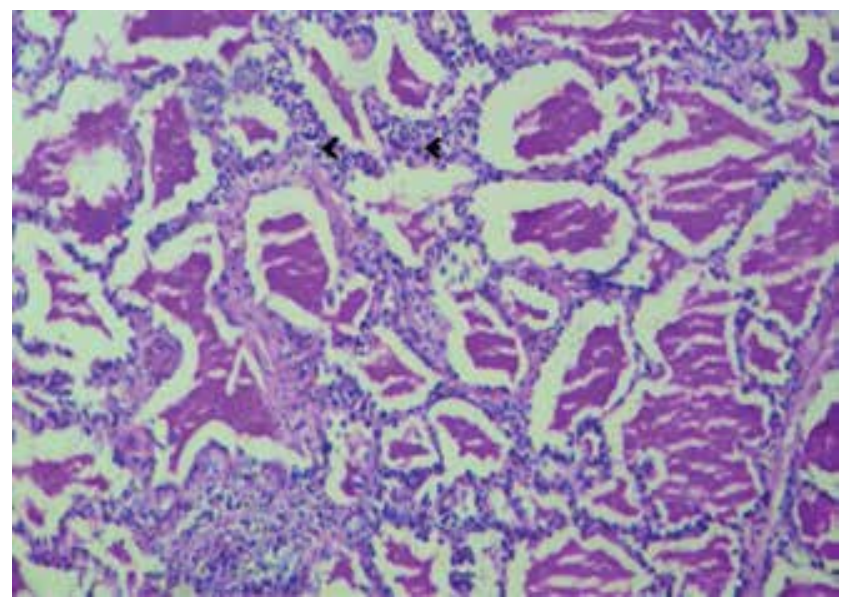

Figura 3. Coloración especial de PAS positiva en el material intra-alveolar. Nótese el infiltrado inflamatorio mononuclear en el intersticio (flechas). 


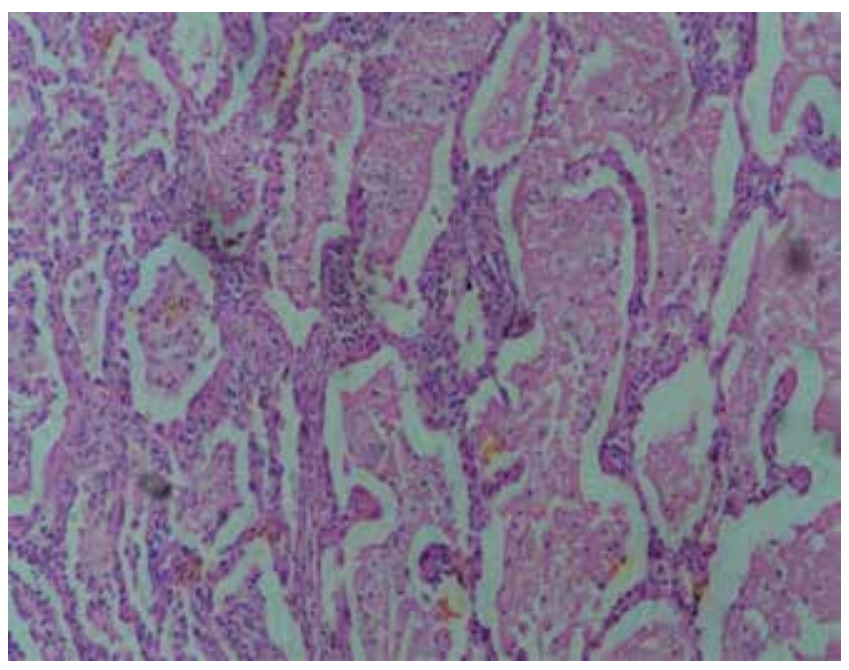

Figura 4. Vista con mayor aumento en la que se observa que el material intra-alveolar contiene macrófagos espumosos y detritus celulares.

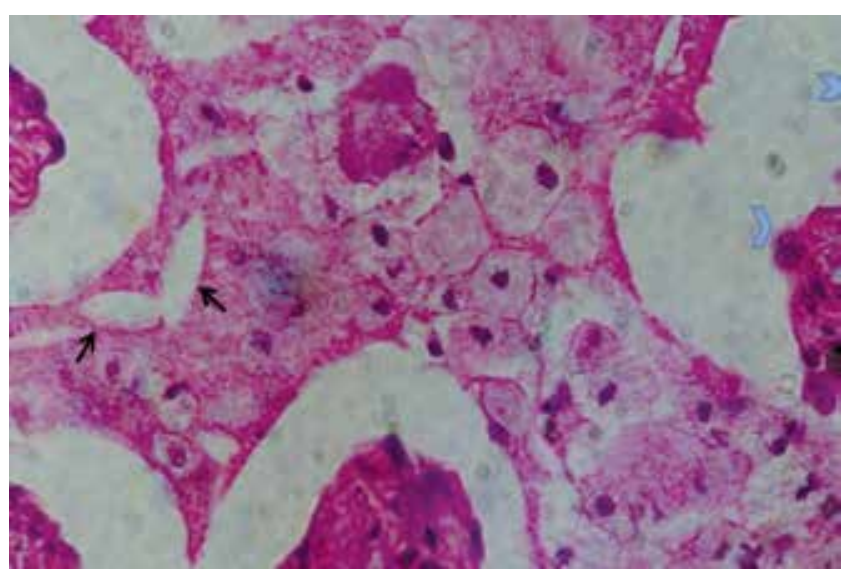

Figura 5. Vista con mayor aumento que muestra la hiperplasia de los neumocitos tipo 2 que recubren los espacios alveolares (flechas azules) y los depósitos de cristales de colesterol (flechas negras).

En controles posteriores refirió mejoría amplia de la sintomatología, razón por la cual se realizó desmonte progresivo de los corticoides y continuó con manejo ambulatorio en rehabilitación pulmonar, indicación de broncodilatador inhalado, optimización de su esquema de inmunización con controles periódicos para determinar la necesidad de lavado pulmonar total y toma ambulatoria de ecocardiograma transtorácico.

\section{Discusión}

La proteinosis alveolar pulmonar también conocida como fosfolipoproteinosis alveolar pulmonar, es una entidad rara de etiología aún desconocida, que se caracteriza por compromiso parenquimatoso difuso como consecuencia de la acumulación anormal de material lipoproteináceo (apoproteínas surfactantes) dentro del espacio alveolar (1). Fue descrita por primera vez en 1958 por Rosen y colaboradores cuando valoraron las biopsias pulmonares de 27 pacientes alrededor del mundo (2) y hasta la actualidad se han reportado aproximadamente 500 casos en la literatura médica (3).

Se estima que la prevalencia de esta patología alcanza los 0,37 por 100.000 personas (4), afectando dos a tres veces más a pacientes de sexo masculino, en edades entre los 20 a 50 años, la mayoría con antecedentes de tabaquismo (3), con remisiones espontáneas de la misma solo en el $20 \%$ al $30 \%$ de los casos.

Aunque su patogenia continúa siendo desconocida, durante los últimos diez años se han hecho importantes avances en el entendimiento de la homeostasis del surfactante y se ha identificado tres formas clínicas de la enfermedad (5). Su forma congénita incluye mutaciones en los genes que codifican las proteína $\mathrm{B}$ o $\mathrm{C}$ del surfactante, como también defectos a nivel del receptor del factor estimulante de colonias granulocíticas (GM-CSF) (6). La proteinosis alveolar secundaria exhibe una reducción en el número de macrófagos alveolares derivada de otras condiciones sistémicas, como por ejemplo las neoplasias hematológicas, las inducidas por fármacos, las infecciones y la exposición a ciertas toxinas ambientales (7). Su presentación adquirida, también llamada idiopática, de la cual se conoce muy poco hasta ahora, parece tener una relación con la presencia de anticuerpos contra GM-CSF $(4,8)$.

Antes de 1994 se estimaba que la patogénesis de esta condición parecía guardar relación con la disfunción primaria del neumocito tipo II, defecto que incluiría una disminución en la depuración del surfactante o por el contrario un incremento en la producción de esta sustancia. Estudios posteriores realizados en murinos modificados genéticamente, permitieron determinar el rol de la deficiencia de 
GM - CSF en el mantenimiento de la homeostasis del surfactante y la influencia negativa de este evento sobre la disminución del catabolismo de esta sustancia a cargo del macrófago alveolar (9). A su vez la presencia de auto-anticuerpos anti-GM CSF en pacientes con proteinosis alveolar pulmonar idiopática, avala la teoría de que esta sea la primera entidad en humanos en la que se producen auto-anticuerpos contra factores de crecimiento específicos, con lo cual se genera la posibilidad de convertirse en una herramienta de diagnóstico para estos pacientes .

La forma idiopática se caracteriza por la aparición de disnea de esfuerzo progresiva e insidiosa durante semanas o meses, frecuentemente acompañada de episodios de tos, comúnmente no productiva, aunque algunos pueden tener episodios de expectoración espesa amarillo - grisácea y, de forma variable, hemoptisis $(3 \%-24 \%)$. A su vez se asocia a otros síntomas sistémicos como pérdida de peso, adinamia y fatiga. Es infrecuente observar fiebre o dolor torácico, excepto en el contexto de la sobreinfección (10). Generalmente pueden encontrarse estertores crepitantes hasta en el 50\% de los pacientes, cianosis en el $25 \%$ e hipocratismo digital en $29 \%$, siendo inusuales las sibilancias concomitantes (11).

Se estima que el intervalo promedio entre el inicio de los síntomas y su diagnóstico puede exceder un año. La radiografía de tórax revela infiltrados alveolares simétricos perihiliares con apariencia en "alas de murciélago", sin signos de crecimiento de cavidades cardiacas, respetando la periferia del parénquima pulmonar, aunque puede existir compromiso unilateral en el $20 \%$ de los pacientes. En ambos casos el compromiso imaginológico no se correlaciona con la condición clínica del paciente. A su vez, la tomografía de alta resolución muestra opacidades con patrón de "vidrio esmerilado" aunque puede observarse compromiso reticulonodular o intersticial en algunas áreas, acompañado de engrosamiento intralobular y septal, hallazgo conocido también como "empedrado" (12).

Es inusual encontrar alteraciones en el hemograma, las pruebas de función renal o hepática excepto por un incremento ligero de la LDH (lactato deshidrogenasa), la cual puede servir como marcador útil de severidad de la enfermedad (3). Con frecuencia las pruebas de función pulmonar pueden ser normales o mostrar patrón restrictivo con compromiso moderado de la CVF, además de hipoxemia asociada al incremento del gradiente alvéolo - arterial, evento relacionado con una reducción desproporcionada de la capacidad de difusión de monóxido de carbono (DLCo), producto del shunt intrapulmonar (13). Recientemente se incluyó la medición de auto-anticuerpos anti GM - CSF séricos y en LBA; los niveles de estos a nivel del LBA se correlacionan mejor con la severidad de la enfermedad, en comparación con los niveles séricos (14). Las muestras obtenidas del LBA son de apariencia espesa, opaca, lechosa, con gran cantidad de sedimento. La biopsia pulmonar abierta continúa siendo el "estándar de oro", pero requiere de un cirujano experimentado para la adecuada recolección de una muestra representativa. Al igual que en la paciente del caso, la histopatología demostró la presencia de alvéolos llenos de material granular, amorfo eosinofílico y acidofílico, que, debido a su contenido de fosfolípidos, se tiñó de rosado con la aplicación de la coloración de PAS (periodic acid schiff), siendo negativa para la tinción de alcian blue, dada la ausencia de glicosaminoglicanos. En general, la arquitectura del parénquima pulmonar está preservada, observándose a su vez macrófagos alveolares "espumosos", hiperplasia de los neumocitos tipo II, cúmulos de linfocitos y grados leves de fibrosis intersticial (4).

De otro lado, el curso de la enfermedad puede clasificarse en tres categorías: estable pero con síntomas persistentes, deterioro progresivo o mejoría espontánea $(4,15)$. Aunque se han probado diversas terapias basadas en sus diferentes mecanismos fisiopatológicos, solo el lavado pulmonar total introducido desde 1965 por Ramírez y colaboradores ha resultado ser eficaz para su forma idiopática (15). Antes de la disponibilidad de esta técnica y en la era pre - antibiótica, 1/3 de los pacientes fallecía por falla respiratoria o complicaciones infecciosas. En la actualidad solo se dispone de algunos estudios retrospectivos que comprueban el beneficio de esta terapia hasta en el $75 \%$ al $95 \%$ de los pacientes, con mejoría significativa desde el punto de vista clínico, radiológico, en parámetros 
de función pulmonar e incluso en la supervivencia, aunque pueden presentarse recurrencias entre el $15 \%$ al $30 \%$ de los casos dentro de los primeros cinco años (3). El empleo de GM - CSF se evaluó en dos estudios prospectivos y se obtuvieron resultados alentadores en términos de mejoría sintomática, radiológica y en parámetros de función pulmonar (16). Por otro lado, su forma secundaria exige además el manejo de la comorbilidad subyacente. Continúan siendo motivo de estudio los beneficios del trasplante del pulmón en este tipo de pacientes, razón por la cual su manejo aún lo constituyen las medidas de soporte (17). Así mismo, se requieren estudios adicionales para determinar el beneficio potencial de otras terapias experimentales tales como la plasmaféresis y la inmunoterapia anti - linfocitos B (18). A su vez estos pacientes requieren seguimientos periódicos mínimo cada seis meses, con control radiológico y de LDH cada tres meses en el primer año para descartar recaídas tempranas. Adicionalmente se necesita de la optimización del esquema de inmunizaciones para patógenos respiratorios, tratamiento de infecciones intercurrentes, medidas de higiene bronquial, protección contra toxinas ambientales, como también el empleo de la rehabilitación pulmonar (3).

Este reporte de caso muestra la forma adquirida de esta patología, con confirmación histopatológica, observándose respuesta clínica adecuada asociada con el manejo de soporte. Lo anterior destaca la importancia de tener en cuenta estas entidades raras dentro del diagnóstico diferencial en la evaluación del paciente con patologías con gran compromiso parenquimatoso pulmonar.

\section{Bibliografía}

1. Shah PL, et al. Pulmonary alveolar proteinosis: clinical aspects and current concepts on pathogenesis. Thorax. 2000;55:67-77.

2. Rosen SH, Castleman B, Liebow AA. Pulmonary alveolar proteinosis. N Engl J Med. 1958;258:1123-42.

3. Seymour JF, Presneill JJ. Pulmonary alveolar proteinosis: progress in the first 44 years. Am J Respir Crit Care Med. 2002;166:215-35.

4. Trapnell BC, Whitsett JA, Nakata K. Pulmonary alveolar proteinosis. N Engl J Med. 2003;349:2527-39.

5. Dranoff G, et al. Involvement of granulocyte-macrophage colony-stimulating factor in pulmonary homeostasis. Science. 1994;264:713-6.

6. deMello DE, Lin Z. Pulmonary alveolar proteinosis: a review. Pediatr Pathol Mol Med. 2001;20:413-32.

7. Garcia Rio F, et al. Six cases of pulmonary alveolar proteinosis: presentation of unusual associations. Monaldi Arch Chest Dis. 1995;50:12-5.

8. Bonfield TL, et al. Autoantibodies against granulocyte macrophage colony-stimulating factor are diagnostic for pulmonary alveolar proteinosis. Am J Respir Cell Mol Biol. 2002;27:481-6.

9. Miyatake S, et al. Structure of the chromosomal gene for granulocytemacrophage colony stimulating factor: comparison of the mouse and human genes. EMBOJ. 1985;4:2561-8.

10. Goldstein LS, et al. Pulmonary alveolar proteinosis: clinical features and outcomes. Chest. 1998;114:1357-62.

11. Prakash UB, et al. Pulmonary alveolar phospholipoproteinosis: experience with 34 cases and a review. Mayo Clin Proc. 1987;62:499-518.

12. Lee $\mathrm{KN}$, et al. Pulmonary alveolar proteinosis: high-resolution CT, chest radiographic, and functional correlations. Chest, 1997;111:989-95.

13. Fraimow W, Cathcart RT, Taylor RC. Physiologic and clinical aspects of pulmonary alveolar proteinosis. Ann Intern Med. 1960;52:1177-94.

14. Lin FC, et al. Clinical significance of anti-GM-CSF antibodies in idiopathic pulmonary alveolar proteinosis. Thorax. 2006;61:528-34.

15. Ramirez J, Schultz RB, Dutton RE. Pulmonary alveolar proteinosis: a new technique and rationale for treatment. Arch Intern Med. 1963;112:419-31.

16. Seymour JF, et al. Therapeutic efficacy of granulocyte-macrophage colony-stimulating factor in patients with idiopathic acquired alveolar proteinosis. Am J Respir Crit Care Med. 2001;163:524-31.

17. Hamvas A, et al. Lung transplantation for treatment of infants with surfactant protein B deficiency. J Pediatr. 1997;130:231-9.

18. Tazawa R, et al. Granulocyte-macrophage colony-stimulating factor and lung immunity in pulmonary alveolar proteinosis. Am J Respir Crit Care Med. 2005; 171:1142-9. 